\title{
The Brain-As-Computer Metaphor
}

\author{
Martin Davis ${ }^{1,2 *}$ \\ ${ }^{1}$ Independent Researcher, Berkeley, CA, United States, ${ }^{2}$ New York University, New York City, NY, United States
}

Keywords: brain, consciousness, algorithm, neural net, operating system

He thought he saw an elephant

That practiced on a fife

He looked again, and found it was

A letter from his wife

-Lewis Carroll ${ }^{1}$

I write as someone who is old (I'm approaching my 93rd birthday) and has a brain. While I claim no expertise in brain science, I hope to suggest questions that might occur to a computer scientist thinking about the brain. What little I have learned about the brain comes from a few books (Patricia, 1986; Dennett, 1991; Hobson, 1994). I have also benefited from lectures by Patricia Churchland, one of the authors.

OPEN ACCESS

Edited by:

Bud (Bhubaneswar) Mishra, New York University, United States

Reviewed by:

Saket Navlakha,

Cold Spring Harbor Laboratory, United States Jantine Broek,

Imperial College London, United Kingdom

${ }^{*}$ Correspondence: Martin Davis martin@eipye.com

Specialty section: This article was submitted to Theoretical Computer Science,

a section of the journal

Frontiers in Computer Science

Received: 25 March 2021 Accepted: 26 April 2021

Published: 22 July 2021

Citation:

Davis $M$ (2021) The Brain-As-

Computer Metaphor.

Front. Comput. Sci. 3:681416.

doi: 10.3389/fcomp.2021.681416
Having an old brain is not wonderful; I can't help but be aware of how much of what it could do when I was twenty is gone. It is so slow. However, this does provide one advantage: Various stages of processes that my brain carries out, that in past years would have gone by too quickly for me to have noticed them, are now quite evident. ${ }^{2}$

\section{DOES THE BRAIN USE ALGORITHMS?}

I ask my friend: "Have you ever read anything by Turgenev?" Her negative reply comes with no pause. Does her brain have a database of fiction she has read? Is her brain using a search algorithm? If not, how else can we imagine this feat accomplished?

I ask: "What's the name of the man you were seated next to at dinner last night?" She doesn't remember. A half hour later, while we were talking about something different, she says"I remember now, Jerome's his name. It just popped into my head." If the brain used a search algorithm to do this, might it be different from that of the previous example, a slower, but more methodical, procedure?

Can we imagine a device made from the brain's "hardware" that can execute search algorithms? Or arbitrary algorithms for that matter? In my (Davis, 2017), I emphasized that very little is needed for Turing completeness. No doubt a universal computer could be built with the brain's neurons. However, it's much less clear that one could evolve. The case of the genetic code in which amino acids are coded by strings suggests that the possibility is not so far fetched. Also in fact, spoken and written language are examples of arbitrary symbols representing objects, actions, and concepts.

Someone crosses a busy street, expertly weaving among the cars. How would one program a robot to do this? Until recently, a process using much numerical computation would be proposed. Nowadays, one could consider the alternative of "training" a multi-level neural net for the purpose. It is certainly easier to imagine brains doing something like this than carrying out a process involving a lot of arithmetic computation.

${ }^{1}$ Carroll, 1991

${ }^{2} \mathrm{I}$ am grateful for the comments of the two anonymous reviewers. 
A student is studying calculus, specifically integration. A bunch of techniques are learned: change of variable, integration by parts, partial fractions. How to decide which to use when presented with a specific example? On the basis of their own attempts as well as access to worked-out examples, students can develop an intuition that guides them to the best choice of technique. Is the student's training like that of a neural net?

\section{VISION AND OTHER BRAIN PRODUCTS}

Scientists studying human vision have shown that what we "see" is the result of complex data processing by the brain. Continuous rapid eyeball motions send huge amounts of data to the brain from which the brain produces the scene presented to us. Our sense that we just see that which is before us is a brain product. We actually "see" a sequence of converging edits (as Lewis Carroll playfully suggests in the quoted excerpt in the heading). With my slow old brain doing the work, early edits are sometimes of sufficient duration that I "see" quite clearly something that isn't there, before the corrected version appears.

How much of our inner mental experience is similarly illusory? Eighty years ago, I was approaching my thirteenth birthday. I remember many things about my life and experiences at that earlier time, but as we have learned, these memories may be unreliable. I have a strong sense that the old man writing this and that boy are different stages in life of the very same person. But isn't that very sense also a brain product?

\section{DOES THE BRAIM HAVE AN OPERATING SYSTEM?}

Many years ago, there was a candy vending machine where I worked. For health reasons, I needed to avoid being tempted by

\section{REFERENCES}

Carroll, L. (1991). The Complete Sylvie and Bruno. San Francisco: Mercury House.

Patricia, S. C. (1986). Neurophilosophy: Toward a Unified Science of the Mind/ Brain. Cambridge: MIT Press.

Davis, M. (2017). "Universality Is Ubiquitous," in Philosophical Explorations of the Legacy of Alan Turing. Editors J Floyd and A Bokulich (Springer), 153-158. doi:10.1007/978-3-319-53280-6_6

Dennett, D. (1991). Consciousness Explained. Brown: Little.

Hobson, J. A. (1994). The Chemistry of Conscious States. Brown: Little. its offerings. One day, passing the machine on my way from my office to the men's room. I was strongly tempted because one of my favorites, chocolate with almonds, had just become available. I resolved to resist the temptation and thought no more about it. As I walked back to my office from the toilet, thinking about a mathematical problem, I noticed that I was eating that delicious candy bar with no memory of having bought it.

This story can be conceptualized as a struggle among three brain processes, we may call: EatTheSweet, EatHealthy, and DoMath. EatHealthy executes and stops EatTheSweet. Then later, while DoMath is going at full blast, EatTheSweet sees its chance and executes. What controls this? In a computer, it would be the operating system that allocates resources to processes and permits them to execute. One can certainly imagine that the multitasking brain possesses some such mechanism controlling its hundreds of processes, some struggling for attention and resources. But an operating system needs a user interface. And where and what is the user?

Our sensation of consciousness and, in particular, our I-me sense of ourself as an individual, have presumably evolved because having them provides an evolutionary advantage. I suggest that functionally, consciousness serves as an interface to the brain's operating system. And furthermore, that the I-me sense, perhaps the most remarkable brain product, functions as the user.

\section{AUTHOR CONTRIBUTIONS}

The author confirms being the sole contributor of this work and has approved it for publication.

Conflict of Interest: The author declares that the research was conducted in the absence of any commercial or financial relationships that could be construed as a potential conflict of interest.

The handling editor declared a shared affiliation with with the author at time of review.

Copyright (C) 2021 Davis. This is an open-access article distributed under the terms of the Creative Commons Attribution License (CC BY). The use, distribution or reproduction in other forums is permitted, provided the original author(s) and the copyright owner(s) are credited and that the original publication in this journal is cited, in accordance with accepted academic practice. No use, distribution or reproduction is permitted which does not comply with these terms. 